\title{
Four Community Engagement Lessons from Detroit to Connecticut
}

Michelle R. Dunlap

Keywords: community engagement

\section{Setting the Context}

One of the first lessons that I learned as a scholar of community engagement was that the term "volunteerism" in the traditional canonical research and literature did not include the kinds of volunteerism that Black folks and other collectivist minority cultures do. Once, while attending a community engagement conference, I overheard some scholars who were huddled together; they were bemoaning that minorities do not volunteer, and they were mystified as to why. At first that sounded normal to me as I had visions of the Red Cross, Salvation Army, hospitals, and other non-profit organizations in my head. However, as I thought deeper about it, I began to think about my own life, growing up in Detroit. I thought of the lives of the many other minorities that I know. I recalled that for the vast majority of us, we come out of the womb volunteering. Our volunteerism may not look like the formal volunteerism that goes on at the Red Cross and other organizations. Nevertheless, our lives tend to be full of volunteerism. We donate and volunteer in our faith-based organizations, as well as in our immediate, extended, and non-blood families. We look after neighbors, church members, and children by the thousands. For hundreds of years, as well as pre-enslavement, we communally looked after one another's children, whether formally acknowledged or not.

I can recall the story of my great-grandfather Elijah, reportedly the biracial son of a young Black woman and her white Jewish enslaver/master. When he was very young, his mother either died, or she was sold away forever. However, nearby lived a kindly enslaved woman named, "Nana", and as was common during that historical period and beyond, she reared him as her own. In other words, someone stepped up and stepped in to do something that they had no legal obligation to do, but they took it on as a moral obligation to look after a child as their own. The enslavement period ended while my great-grandfather was still relatively young. Because of Nana's upbringing of him, he was able to go on to accomplish remarkable things: carpentry, marriage, seven beautiful children, and a devoted life of evangelism that included daily devotions with his seven children when they woke up and before they went to sleep. He and his children, with their own hands, built a rather large house that still stands to this day, a house that remained in our family until his last child died in 2007 at the age of 100. The tradition of family members stepping in and rearing children as needed is one that is familiar, if not common, to most African American people as well as Native Americans, Latina, and many other cultures.

Having said all of this, I bring you to my life and its evolution into the discipline of community engagement. I too am a multiracial person — reared by a biracial father, a white Irish/French grandmother, an African American mother, and an African American stepmother. Twenty-five years ago, I entered a tenure-track position as the first African American in my Department. Six years later, I became the first African American woman in the history of the college to start as an 
assistant professor and secure promotion and tenure. Eight years later, I not only became the first African American woman at the college to achieve these milestones, but also first to go on to achieve Full Professor status. It's not that I am so special or smart, or that my college is unusually difficult for domestic minorities (in fact, I have tended to find the opposite to be true). Rather, academic environments in general historically have not been climate-friendly for the very minority groups who gave their blood for and/or built this country. I hope that in this new millennium, things are shifting for the better in academia. However, I cannot tell my story of community engagement without setting this context. Not only was I a trailblazing-first in many ways in my academic institution, but also among all of the cousins and siblings of my generation on my mother's, my father's, and my stepmother's side. Among all of them, I was the first to earn an undergraduate degree. Therefore, I also was the first among my familial generation to earn a Master's and Doctorate. Making my experience even more unique, was that when I began my tenure-track position, I had already spent three years as the guardian of a precious six-yearold nephew, and to my delight I ended up rearing him a total of 15 years until he was 18 .

So, I started my full-time academic career as a single parent of a young child. By the time my oldest was 21; he was entering the Armed Services, I was both coming up for full promotion and becoming a parent again. This time it was to a just-as-precious 7-year-old whom I adopted, and who now is almost grown. About four years into my rearing of him, I joined the "sandwich generation" as my mother's primary caregiver. She is a survivor since 2013 of lung cancer with metastasis to the brain. To date, she has received not only radiation, chemo, and oral chemo, but also four "gamma-knife" surgical procedures to remove brain tumors. So, a Black, single, auntiemomma, Ph.D., professor, primary caregiver, scholar - that is what I have been while also blazing a trail within academia and the disciplines of service-learning and community engagement scholarship.

Therefore, as I set this context, I may not have put in many hours as a volunteer at the Red Cross or the Salvation Army, but like many minorities, I have hundreds and thousands of hours of undocumented volunteerism that I do not think of as volunteerism-it is just "what we do". It took me hearing the muttering of scholars at a conference to argue defensively within myself that what many minorities "just do" is also volunteerism. Moreover, informal and undocumented volunteerism is just as much or more than what others do formally, as well as just as valid and important. Understanding the validity of informal and undocumented volunteerism that is the norm within many minority or collectivist cultures would be the first important thing that I would want readers to take from my experience as a scholar of community engagement. I use the concept of volunteerism to make this point in the strongest terms: please remember to question assumptions with respect to the communities we engage, hearing directly from the community itself at the most basic level before framing studies, theories, and policies.

Thus, for an overview, I present four lessons for the field or for other community-engaged scholars:

1. Question assumptions with respect to the communities in which we are engaged (discussed and illustrated above). 
2. Conduct, support and publish more community-engagement research with students of color and communities of color at the center, and not in juxtaposition to normalized views of white culture.

3. University or college funding opportunities to help support community-requested or negotiated engagement are a necessary and important investment.

4. When engaging with communities outside of the classroom, you, your students, and your administration have to be willing to take measured risks.

\section{Crossroads and Difficult Research Choices}

When I first started my career, I found myself interested in two different, but somewhat related issues. I originally wanted to publish a series of papers based on a pilot study that I had conducted with 159 students examining their perceptions and misperceptions of the partially fictionalized African American family in Spike Lee's Crooklyn. While I was pursuing that, something had been brewing among my students. At that time, except for an occasional minority here or there, they were almost all white. For the majority of them, I was the first African American woman in a position of authority that they had personally encountered, which in itself had the potential to be a challenge and often it was. In addition, when I arrived at the college my Department Chair at the time told me that in most of their classes they sent their students out into the very economically and racially diverse community to do practicums. Concurrently, our Office of Community Partnerships (Volunteers for Community Service or OVCS at that time) was using the language of "service-learning." I quickly understood that these two experiential forms of learning were the same within the context of our Department, and I happily incorporated service learning into my very first curriculum, and have done so ever since. During the first two-years of incorporating service learning, I noticed a pattern of at least $25 \%$ $75 \%$ of my students expressing during class or coming to me in my office to express anxieties about their experiences in the community. Some expressed feeling unwelcomed, feeling nervous, or feeling ill prepared. Initially, I had a hard time understanding why they were so anxious, as I came from extremely diverse communities within Detroit. I was puzzled, and I could not understand why the students were making such a big deal about going out into the community.

When I asked my colleagues if their students were having similar difficulties, they reported that they did not seem to be experiencing the same distresses that my students were. I began to realize that in comparison to my department mates, perhaps there was something about me, a relatively younger (by roughly 15 years) Black woman, sending the students out into less privileged environments, that made the students feel even more uncomfortable. In addition, perhaps the diversity-oriented journaling prompt questions that I asked were engendering discomfort, e.g., "how do you see your life as being different from the community with which you are engaging?" Further, I began to notice that the themes emerging about their discomfort and their means of coping were sounding more and more similar each semester. I became more and more interested in their adjustment process, and I was motivated to want to help them understand their own process so that I would not become a sacrificial victim of it. In these efforts to both understand their issues and to help protect myself by illustrating their process, I decided that I would like to study their journals systematically. For the next few years, at the end of each semester after all grades were turned in, I asked for volunteers willing to submit their journals for study, inclusive of written permission. Students submitted their journals by the dozens, and as they did, I 
anonymized their journals so that I could solicit assistance from my ongoing student research team with coding. We were able to develop a coding system for documenting the hundreds of issues that emerged within the student journals.

Concurrently, I had been working on the Crooklyn pilot study mentioned earlier. However, I found myself at a critical point. I needed to decide which of my two beloved research studies to focus on, as the tenure clock was ticking loudly. There was the pilot study where students had watched the first 15 minutes of the African American family in Spike Lee's Crooklyn, and then evaluated the family on many different dimensions. Then there was the service-learning studies involving systematic analyses of my students' journals. I felt a need to focus on one or the other for a time, in order to produce a cohesively connected series of journal articles, but I also felt torn between the two lines of research. It was 1995, and one line of research looked at how people perceive and misperceive Black families, while the other examined what mostly white students go through when they go out into minority communities. This second line addressed helping service-learners with their adjustment issues so that they can go out more composed and prepared, and thus do a better, more culturally sensitive and appropriate job of engaging with the community. I felt motivated to produce scholarship that would help my and other students around the country, no matter what their background. My project would aid them to go out, do good work in the community, and treat the community as their partners rather than as stereotypes. Either of my two areas of interest and corresponding data collections could accomplish this. The passion was within me for both areas, but the practical question for me was whether I could finish one more quickly than the other within the time constraints of the tenure clock.

Ironically, it was around that same time in 1995 or so that I came across an article by Yolanda T. Moses, a former President of the now defunct American Association of Higher Education (AAHE). The article was in an educational magazine that I have not been able to locate in recent years. I do recall that, in the article, Dr. Moses said that Black women need two lines of research, one for themselves, and one for their careers. At a conference that I attended shortly after that, I mentioned this to a couple of my Black women colleagues. One recently tenured Black woman seemed quite offended by it, saying that all of her research is for her. My response was that I was glad that she was in an environment or context where she could feel that way. However, I wasn't so sure that my environment had evolved to that place yet where I didn't have to worry about the practicalities of what happens to the research when it leaves my desk to be evaluated by journals, and how that could impact a tenure decision. I decided that since my pilot study was conducted with college students and not practicing social service providers, I would put it on the back burner, and would put all of my energies into the analyses of service-learning journals and production of publications from that. I wonder now if I was actually bifurcating my research in the manner that Dr. Moses suggested, with the service-learning studies being for my career, and the Crooklyn studies, which I would save for later, being for myself? In any case, her advice helped me to emotionally detach from one and strategically develop a plan for moving ahead with the other with tenure in mind. I moved forward, publishing many research articles on the multicultural service-learning process, as well as a book and two edited volumes.

With the help of my mentors, I also was strategic about the journals that I targeted for my service-learning work, and I did find most journals to be receptive to what I had produced. The 
qualitative and quantitative analyses conducted on the student journals found, for example, that most students feel anxious as they begin their service-learning, but if they can just get past the first few visits without quitting, the vast majority will feel much better and will even enjoy their service-learning (Davi, Dunlap, \& Green, 2008 \& 2010; Dunlap, 1998a). Other publications examined, for example, the actual multicultural issues that service-learners and facilitators of community engagement report and how they resolve them (e.g., Dunlap, 1998b \& 2000; Dunlap \& Webster, 2009; Evans, Taylor, Dunlap, \& Miller, 2009). My colleagues and I explored how male service-learners respond differently to affection from girls and boys compared to female service learners (Dunlap \& Coughlin, 1999). Using a Piagetian model of assimilation and accommodation, we looked at how service-learners working at homeless soap-kitchens view their identity in relation to their service-learning partners (Dunlap, Scoggin, Green, \& Davi, 2007). We discovered how racial identity development occurs within the classroom and community engagement process (e.g., Davi et. al., 2010; Dunlap 1998c, 2000, 2011, \& 2013), and how frustrating it can be engaging in communities where people "see no color" (Dunlap, Burrell, \& Beaubrun, 2019).

A decade and a half after I first read Dr. Moses' extremely helpful article, and after earning tenure and coincidentally full promotion, I returned to my Crooklyn work, collecting the same kind of data but this time from 200 social service providers from different seven agencies. I am now in the process of creating a similar series with this work as I did with my service-learning work. Like concentric circles, I have moved from service learning to broader circles of community engagement (e.g., social workers, minority shoppers and their experiences, etc.). The first Crooklyn journal article published illustrates that as service-providers' claims of being colorblind grow stronger among the participants, the more likely they are to see the children depicted in first 15 minutes of Crooklyn as aggressive and out of control, even when controlling for race, education, and other demographic variables (Dunlap, Shueh, Burrell, \& Beaubrun, 2017). I see this line of work as potentially making a significant contribution to the community engagement and cultural competency bodies of work, because they challenge those who work with children and families to consider their own personalities, biases, and upbringing experiences as they engage with the community.

I am in the process of submitting similar articles with respect to social service providers' symbolic racism scores and a variety of other variables. I also am working on a book based on interviews with mostly minority people around the country about their experiences trying to do something as simple as shop. Their stories also have everything to do with community engagement, as individuals go outside the safety and security of their homes into a consumer marketplace that often has very negatively stereotypical views of minority customers as thieves. The incidences described in the storytelling reveal a complexity that the national and international public has just recently been able to peak into with the recent Starbucks and similar incidences.

All these years later, as I compare the publication processes of these three different lines of research, it may be coincidence, but I believe my scholarly works that force white people to look at themselves are much more challenging to advance in the academy than my service-learning work. The former studies how they judge minority children, or how they treat minorities in the consumer marketplace. The latter focused on predominantly white students and their adjustment 
in the service-learning process. Therefore, back in 1995, whether idealistically it was right or not, I get the impression that I made the right choice for my career when I pushed the one area forward, and delayed the other areas for another time when my career was more secure. That does not make me feel proud, and I put the blame for this on academia and what before now it has preferred to examine critically. Academia has preferred looking at white adjustment needs, while also analyzing communities of color through an unquestioned, often pathologizing, white norm.

I would like to see academia more heavily shift its values to the point that it finds minorityfocused work of as much concern and interest as work that advances the dominant culture's needs and analyzes its norms. This point brings me to the second lesson, which is on decentering the dominant narrative in our research. That is, more research needs to be supported, conducted and published with students of color and communities of color at the center, and not in juxtaposition to normalized views of white culture. Therefore, academic research and publications centered on non-stereotypical, culturally relevant minority experiences as well as critiques of dominant cultural norms should stand as just as valid as research centered on the needs of dominant culture, and should be advanced as such in journals and books and in tenure, promotion, and grant-funding processes. Likewise, scholarly research venues should foster and nurture minority scholars and students' and other constituencies' experiences and critiques of dominant white norms, especially within community practice and engagement.

\section{New Supports, New Directions}

To personally meet and engage with Mrs. Carla Lynton and the NERCHE staff in the process of receiving the Ernest Lynton Award in 2008 was a great honor that was very validating for my work and me. I received the Lynton Award just prior to coming up for full promotion. I traveled to receive the award accompanied by two of my student research team members who copresented with me at the Coalition of Urban and Metropolitan Universities (CUMU) conference in Louisville, Kentucky. This was the experience of a lifetime, and to be able to share it with two of my students was incredible. The two students were so excited that they must have taken what easily could have been 500 or more photos. My other students, their classmates, helped us practice for our presentation prior to leaving, which in itself was a further bonding experience for all of us. To now see these two students go on to receive Masters degrees and to continue on their path to engaging in work with children and families as well as co-authoring communityengaged scholarship is very rewarding for me and anyone involved with them. The Lynton Award now goes solely to pre-tenure scholars, and that makes a lot of sense because it is so validating to one's community-engaged career. Community-engaged research can be seen as less valid, or therefore soft, in comparison to other fields of inquiry, when actually it can be extremely difficult, time-consuming, and even more risky in comparison. To have the Lynton Award to help validate pre-tenure contributions is a greater affirmation of the field.

In the past decade since receiving the Lynton Award, not only has my writing, but also my community engagement, have taken several very interesting turns. For one, my community engagement has extended from my students' service learning at various sites of their choice to include focused, project-based endeavors. With support from several internal grants, such as the Connecticut College Margaret Sheridan Faculty Engagement Grant, and the International 
Curriculum Development (ICD) Fund, my students and I have become better financially equipped for engaging in exciting community engagement and learning endeavors. Through grants ranging from $\$ 500$ to $\$ 3,000$, as well as seeking support from other offices on campus, these endeavors have included traveling, providing collaborative community education, hosting community guest speakers to our classes, organizing and hosting community based workshops, and conferences that bring the community and the college together.

For example, students of my HMD 302 Social and Personality Development, HMD 307 Adolescent Development, and HMD 111 Introduction to Human Development have traveled in partnership with community youth to Harlem New York, as well as to a variety of conferences, museums, performing arts events, and cultural banquets that relate to our courses. The purpose of organizing such field trips is to encourage collaborative intellectual and social engagement across and within these partners regarding human developmental and social justice themes. For the past year and a half, students of my HMD 302 Social and Personality Development and my HMD 307 Adolescent Development courses also have engaged with community partners to develop parent training workshops and resources to strengthen family communication and child rearing. To extend the life of our project, my students and I have developed a parenting support video page that documents our activities and posts student-developed educational information and trainings requested by our community partners (Parent Support Group Video Resource Page, 2018).

To elaborate further on our engagements, for the past few years, with help from the above grants and other campus donations, my students and I have consulted with community partners to ask what educational opportunities they would like us to develop in partnership with our courses. One of these collaborations resulted in a full-day conference titled, "Flippin' the Script: Challenging the Strongholds and Systems that Hold Us Back" that brought together 90 community youth, parents, college students, faculty, and administrators for a day of mutual sharing and learning. The workshops that were requested by the community, and subsequently provided, all centered on empowering the community financially, physically, emotionally, and educationally. My students and I also have hosted numerous youth, youth leaders, and other community partners as visitors to our courses. In addition, thanks to funding, we have hosted many youth and adult community partners for lunch and dinner with our class at Connecticut College's Harris Dining Hall for collaborative dialogue, interpersonal fellowship, and crosscultural learning.

This semester, my HMD 307 Adolescent Development students added seven new videos to our parent support video page to help community teens and their parents deal with social media issues including cyberbullying, internet safety, and critical thinking (Parent Support Group Video Resource Page, 2018). We also hosted a conference this past May to introduce the students' new videos to the college and community, and to engage with community partners on these issues. In addition, we highlighted the video page and its new videos at our class-sponsored monthly parent support-group. I now assign these videos early on in my courses so that my students can learn from their past classmates, and be inspired to envision new video projects for themselves. Thus, to recap, in order to invest in, promote, and further advance classroomcommunity collaborations, and especially equitable ones, funding opportunities are needed. In addition, finding ways to extend the life of such educational opportunities and engagements 
using technology or other resources, whenever possible, is helpful for sustaining a potential mutual learning impact.

\section{Challenges and Risks}

Service-learning and other education-based engagements are so much more risky than conventional classroom learning. When we take our students, teaching and/or research offcampus, typically we do not have the same control over the variables that could affect us as we do within the confines of the classroom. As examples, there are a few situations that I found particularly challenging when engaging with community environments.

Several years ago, when my students and I were collecting diversity-related data over a period from one of several data collection sites, one of the white participants took issue with my questionnaire and its implementation. She seemed upset that the questionnaire had racially focused questions. Further, she accused me of giving an unapproved scale, the MMPI clinical assessment, on my questionnaire (I did not). In spite of my trying to quell her concerns and explain what the questionnaire actually contained, she went forward and complained to a State regulatory agency. This caused me, and the 35 participants of that particular day, to be interviewed about our process as part of an investigation that lasted for a two-week period. Having to tell this to my college's Institutional Review Board (IRB) - of which I was a committee member myself — and to my Dean of Faculty, was embarrassing, to say the least. Worse, I had to live through the investigative process for two weeks not knowing if the regulatory agency would confiscate my data, or even if the agency would forbid me to conduct research ever again in my state, which I was told could happen. The two weeks of waiting were torturous. Research has always been an important part of my career, and truly an academic passion. During those two weeks, my hair fell out, I broke out into stress-induced psoriasis, and then I contracted the Shingles.

The investigator came to interview me last, at the end of the two-week investigative process. We met at my office, and I was not sure what to expect. She was a white woman who greeted me warmly, but I still was extremely apprehensive. I had prepared extensive notes, detailing the rationale behind my entire process, including its every step and how it lined up verbatim with my distributed informed consent and my IRB approvals. After shaking my hand and introducing herself, she sat down and made herself comfortable. I was expecting her to interview me, but instead, she told me that she would tell me what happened that day, and she proceeded to go over the whole data collection process step by step, in full detail from the moment I walked into the room that morning. She spoke as if she herself was there. Puzzled, I asked her how she knew every little detail, or what I said and did as if she herself was there. She explained that every person she interviewed as part of the investigation reiterated to her identically the details of the research process. Then she apologized for all of my trouble, letting me know that I was found not-guilty of any wrong-doing, and giving me a letter documenting her finding that I could pass on to my institutional IRB. Her sincere, even emotional apology to me for what I had endured was something that I will never forget.

Because one person out of dozens misunderstood the intent, purpose, or process of my study, I found myself in the midst of what felt like the worst disaster ever. These are the sorts of 
misunderstandings, challenges, and risks that can happen when we take our work or even our students outside of the classroom. Someone can misunderstand our intentions, our materials, our style of dress, or our communication. During those two weeks of waiting, I vowed that I would never engage my academic life with the community again. However, that vow did not last very long. Because we engage in communities, we are able to accomplish unique endeavors that may have a significant positive, swift, applied, and/or relevant impact on the community, our students, and ourselves, and that is difficult to give up. Being able to bring knowledge to parents confused about their teenagers' development, or to collect data from people who actually work with children and families every day, or to take students together with children, teens, and/or elders, some of whom have never been outside of a 10-mile radius of where they live to see places they have only heard of is so rewarding - to museums, theatres, libraries, festivals, and other cultural events, all of these kinds of endeavors seem mutually rewarding to all involved. Being able to process with my students and community members, both together and separately, is also where a great amount of our learning occurs. Community engagement is therefore more challenging, and sometimes riskier. Nevertheless, in 25 years of academic and community engagement, the above instance was the most upsetting, and thankfully, nothing else has come anywhere near close to it for me.

The next thing that I find most challenging is that sometimes it is difficult for me to accept when I want more for a person or persons I am working with in the community than they want for themselves. Sometimes I find it painful to accept a person's choice not to pursue better for themselves when that better may appear easily available by my (mis)perception. But I have to remind myself that my perception is not necessarily their perception nor their reality. My initial perception often is not the correct perception, and surely not the only perception. Related to this, is my frustration when community partners seem not to be open to new opportunities because of fears or stereotypes. For example, I can recall being extremely frustrated when I was trying to bring two U.S. predominantly poor and immigrant Protestant church congregations together with a Catholic Church congregation in East Africa that works with refugee families. Using technology, I wanted my students to collaborate with all three churches so that we could work together on issues that may be affecting all three of the communities. However, as I was attempting to organize the collaboration, I found that the Catholic congregation representatives did not want to work with the Protestant churches, and the Protestant congregations' representatives did not want to work with the Catholic congregation. I myself have worked for years with US Catholic and Protestant leaders so on the day that I realized that my vision for my students was going to be thwarted due to religious intolerance, I found myself extremely disappointed, even almost depressed. I felt so disillusioned - to hear of such still lingering prejudice between denominations - that I cried. Once I dried my eyes, however, I accepted that the options were coming down to my students working with one denomination or the other because the Catholics and Protestants with whom I was engaging were not going to work together. Therefore, I went with the one that logistically would be more feasible logistically and hands-on for my students. However, my sadness about such remaining religious intolerances still lingers at times.

On a related note, I had a situation once where my students and I were working with an ethnic, faith-based organization to try to strengthen parenting strategies. We organized a cultural, educational field trip for the families to a theatre to see a Native American 
storyteller/singer/musician performance. The purpose of the field trip was to help model for parents how to better utilize educational and cultural resources in our community, as well as model methods for engaging their children on themes related to such events. When seeking feedback from the church about events that would interest their youth, they had warned me that they would not attend any events with "dance" (as they viewed dance as sinful), but that any other cultural events would be okay. Accordingly, my students and I were careful to pre-screen the cultural/educational events that we located for consideration to be sure there was no dancing in them. After much vetting of events, we selected the Native American theatrical performance for its artistic and cultural diversity, as well as its historical and educational potential, and its logistical and cost-effectiveness. Excitedly we purchased 40 tickets with our grant funds and informed the church leaders of the specific event that we had planned for them based on their initial feedback. Then to our surprise, they would not accept our invitation because the description of the event included "jazz", which, unbeknown to us, also was seen as sinful.

Initially the students and I were devastated. Afterward, we used it as a teachable moment, understanding that when organizing activities, there is always the risk that not everyone will be happy or satisfied with all aspects of it. In our processing, we emphasized that we cannot pretend to know what any community group wants or needs, i.e., we cannot impose our values on any group. Thus, just because we had the perspective that the event we had organized would be appropriate and valuable, does not mean that it was. We reaffirmed that we must be respectful and understanding of their worldview. Therefore, we brainstormed on other youth organizations to whom we could extend the invitation. In the end, on the evening of the event, we filled all of our seats with 40 community youth, college students, and community elders who attended dinner in the student cafeteria and then moved forward to the theatre for the event. It turned out to be a wonderful evening of sharing, networking, laughter, enjoyment, and most of all, learning. Many in the community are still talking about their event. Likewise, my students and I learned a great deal about measured risk-taking and resourcefulness through that experience which we will cherish.

I offer one more example of the kinds of difficulties that can come with taking our learning outside of the classroom. One of the greatest challenges for me was watching a local non-profit with which I was heavily engaged lose its building because it would not consider other perspectives, feedback, assistance, or resources. I, and often my students, had been a supporter of the non-profit for more than a decade. But my and other supporters' advice about how to reach sustainability was never taken seriously - things like forming an active board; developing equitable policies for its participants; creating a short and long-term financial plan with accountability. While the non-profit still exists, a great deal of its resources goes toward renting space rather than increasing equity in a space of its own. Therefore, there is very little funding available for anything else, and no space for programming without having to pay additional rental fees. Once ownership of their space was lost, I found it difficult to continue to utilize my health and energies toward their mission without a plan for organization, consensus, sustainability, and accountability. In other words, I was not willing to continue to risk my students' time and resources (and my own) toward a non-profit that was not attempting to attend thoughtfully and strategically to its sustainability, even to the point of refusing helpful educational and training resources for more than a decade. While I remain connected to those involved in the endeavor, I have not been willing to engage my students or my energies and 
resources working to assist the non-profit, until they have made an effort to develop a plan for equity, accountability, and sustainability. I decided not to continue to take the measured risks with this organization. Reluctantly yet firmly, my students and I cut our losses and moved on.

Therefore, when engaging with communities outside of the classroom, you, your students, and your administration have to be willing to take measured risks when you feel that it is appropriate. However, you also have to self-care, knowing where your limits and boundaries are so that you can stay healthy and whole yourselves. Unfortunately, this sometimes may mean deciding not to take a risk, as well.

To review, and to sum, my advice to community-engaged scholars (and those mentors and institutions that support them) is to continually question assumptions with respect to the communities in which we are engaged. Further, as we work to unfold research programs, we should be sure to listen carefully to the communities with whom we partner when developing our research questions and methodologies, being sure to frame our work equitably, and ways that allow everyone to learn, including ourselves. We need to be sure to utilize or push further for university or college funding opportunities that help support community engagement and research. Finally, when engaging with communities outside of the classroom, consider taking very carefully thought out and measured risks with input from the community, but also know where your self-care and/or ethical limits and boundaries are so that you can take full pride in your work over the life of your career and beyond.

So many aspects of my career have helped me to grow as a scholar: the multicultural contexts and ways of seeing and experiencing the world; the older and newer research opportunities; tremendous mentoring; grant and other financial supports; community partnerships; award recognitions such as the Lynton Award, and the tenure and promotion validations. Many challenges I would have preferred to do without, but yet have taught and stretched me. All together, these lessons have made me a keener, more compassionate, more grateful communityengaged scholar. I hope that my experiences can help younger scholars coming along, who are trying to find their way and their stronger voices - but in a balanced manner. That is, in a manner that both supports their humanity and stretches them to grow as scholars while also finding satisfaction and pride in their work. As I have and I am very grateful.

Likewise, I hope that institutions will make community-engaged scholarship and funding a greater priority as we consider the challenges that communities are facing such as social injustice, the preschool to prison pipeline, health disparities, early intervention, policeinvolved shootings, mass shootings, environmental racism, non-prescription and prescription drug epidemics, gentrification and re-gentrification, homelessness, sextrafficking, and on and on. Not to further illuminate the problems, but rather to illuminate the solutions in order to find the resiliency factors, public policy commitments, and other variables that can help to ameliorate these challenges so that our communities can better thrive as full partners with us. 


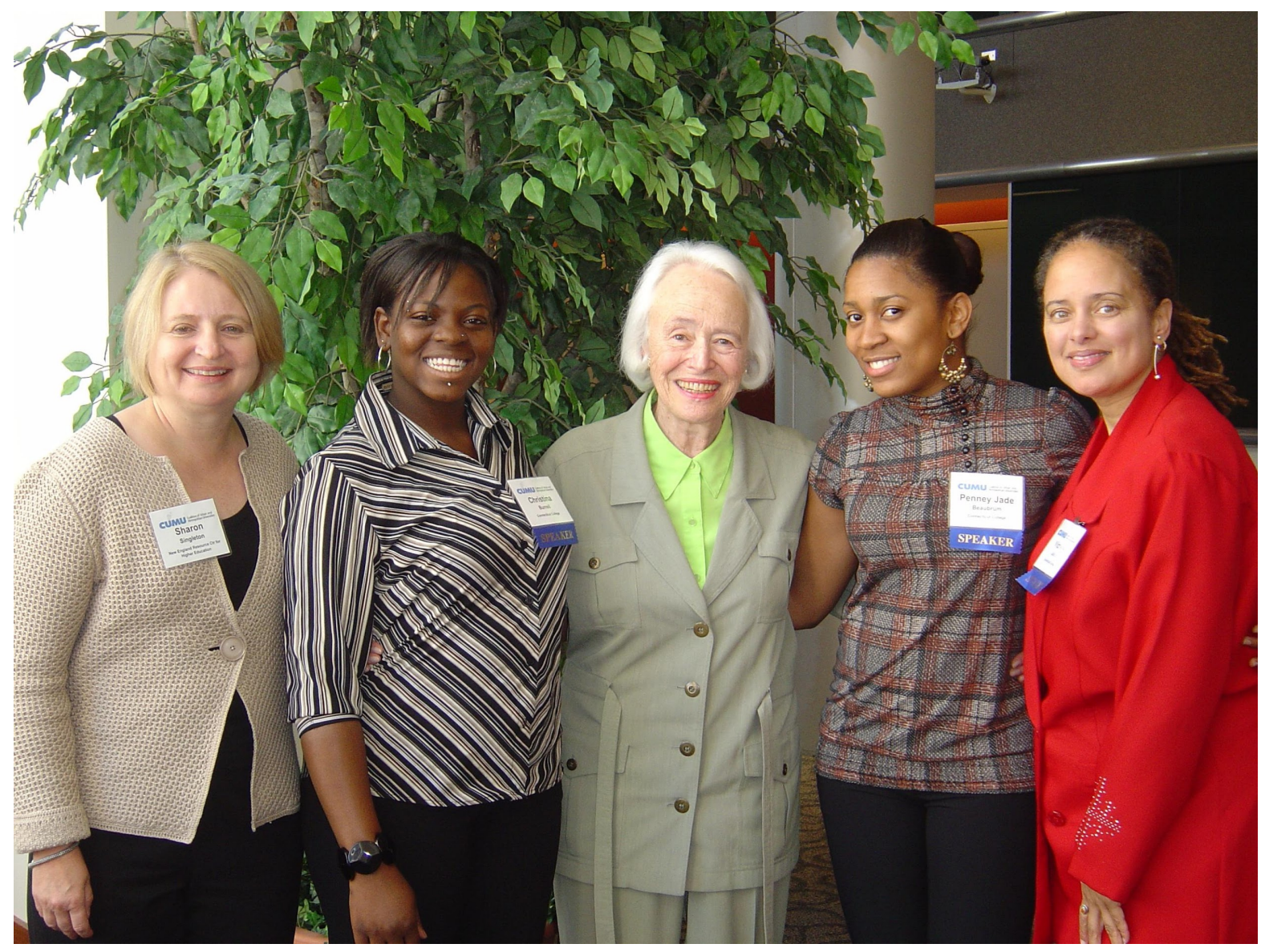

Figure 1: From left: Sharon Singleton, NERCHE; Christina Burrell, Connecticut College Alumna, class of 2011; Carla Lynton (beloved widow of Ernest Lynton); Penney Jade Beaubrun, Connecticut College Alumna, class of 2011; and Michelle Dunlap, Connecticut College, and Lynton Award Recipient, (Lynton Awards Ceremony, Brown University, October, 2008). 


\section{References}

Davi, A., M. Dunlap, \& Green, A.. (2008). Feminist ways of seeing: Preparing students for service learning. In K. Dugger (Ed.), Handbook on service learning in women's studies and the disciplines (pp. 14-25). Baltimore, MD: Institute for Teaching and Research on Women.

Davi, A., M. Dunlap, \& Green, A. (2010). Exploring Difference in the Service-Learning Classroom: Three Teachers Write about Anger, Sexuality, and Justice. In T. Deans, B. Roswell, \& A. Wurr (Eds.) Writing and community engagement: a critical sourcebook (465-484). Boston, MA: Bedford/St. Martin's Press.

Dunlap, M. (1998a). Adjustment and developmental outcomes of students engaged in service learning. Journal of Experiential Education, 21 (3), 147-153. https://doi.org/10.1177/105382599802100307

Dunlap, M. (1998b). Voices of students in multicultural service learning settings. Michigan Journal of Community Service Learning, 5 (1), 58-67. Retrieved from http://hdl.handle.net/2027/spo.3239521.0005.106

Dunlap, M. (1998c). Voices of Students in Multicultural Service Learning Settings. Michigan Journal of Community Service Learning, 5 (1), 58-67.

Dunlap, M. \& Coughlin B. (1999). College student affection issues in child and family focused community service-learning settings. Academic Exchange Quarterly, 3 (4), 28-34. [Reprinted in Linda Serra Hagedorn, Ph.D. (Ed.), Sound instruction: ready to use classroom practice, 2001, Chatanooga, TN: Rapid Intellect Group.]

Dunlap, M. (2000). Reaching out to children and families: students model effective community service. Lanham, MD: Rowman \& Littlefield Publishers.

Dunlap, M., Scoggin J. M., Green, P. \& Davi, A. (2007 Spring). White students' experiences of privilege and socioeconomic disparities: Toward a theoretical model. Michigan Journal of Community Service Learning, 13 (2), 19-30. Retrieved from http://hdl.handle.net/2027/spo.3239521.0013.202

Dunlap, M. \& Webster, N. (2009). Enhancing inter-cultural competence through civic engagement. in B. Jacoby (Ed.), Civic engagement in higher education (pp. 140-153). hoboken, nj: Jossey-Bass Publishers.

Dunlap, M. (2011). Thriving in a multicultural classroom. In C.P. Harvey \& M.J. Allard (Eds.), Understanding and managing diversity. Upper Saddle River, NJ: Pearson/Prentice Hall.

Dunlap, M. (2013). Cross-cultural community engagement, Elizabeth Kubler-Ross's model of death and dying, and racial identity development. In H. Fitzgerald, J. Primavera, and C. Burack's (Eds.) Going public: civic engagement, The scholarship of practice, E. Lansing, MI: Michigan State University Press. 
Dunlap, M., Shueh T. F., Burrell C., \& Beaubrun, P. J. (2017). Color-blind ideology and perceptions of minority children during a fictionalized parent-child discipline scene, Journal of Ethnic \& Cultural Diversity in Social Work, 27 (2), 193-213.

http://dx.doi.org/10.1080/15313204.2017.1344946

Dunlap, M., Burrell C., Beaubrun, P. (2019). Moments in the danger zone: Encountering "nonracist," "non-racial," "non-color-seeing," do-gooders. In S. Evans, A. Domingue, \& T. Mitchell (Eds.), Black women and social justice education: legacies and lessons. NY: SUNY Press.

Evans, S., C. Taylor, M. Dunlap, \& D. Miller (2009), African Americans and community engagement in higher education: Perspectives of race in community service, service-learning, and community based research. NY: SUNY Press.

Parent Support Group Video Resource Page (2018). Home. Retrieved from https://www.youtube.com/channel/UCcq4IYXN4YyoaSJRDPQwVFw/featured 


\section{Author Information}

Michelle R. Dunlap

Professor of Human Development

Connecticut College

Box \#5223

270 Mohegan Ave.

New London, CT 06320

Telephone: 860-439-2634

Email: mrdun@conncoll.edu

Pr. Dunlap graduated from Wayne State University with high distinction and with honors in psychology. She has served on the faculty of the human development department at Connecticut College since 1994, and served twice as Faculty Liaison to the Connecticut College Children's Program in 2000-2001 and 2006-2009. She has written journal articles, book chapters, and essays about her research involving college students working in community service-learning settings; intergroup relations; and perceptions and misperceptions of African American child rearing. 